SHORT REPORT

\title{
Informed consent in trials for neurological emergencies: the example of subarachnoid haemorrhage
}

\author{
R Schats, E H Brilstra, G J E Rinkel, A Algra, J van Gijn
}

J Neurol Neurosurg Psychiatry 2003;74:988-991

Background: In patients with acute life threatening diseases, and in their relatives, the ability to make a balanced decision on participation in a clinical trial may be impaired.

Objectives: To assess what relevant information could be recalled by patients who were living independently after a subarachnoid haemorrhage, and by their relatives; and to determine how these patients and relatives had reacted to the informed consent encounter.

Methods: Twenty months (range 7 to 31 ) after treatment for subarachnoid haemorrhage, 49 patients and 47 relatives who had participated in one of two randomised trials on medical management were interviewed. The interview consisted of items on: spontaneous recall and knowledge of trial design; understanding of the trial design and the informed consent procedure; the amount and clarity of the information given; and reasons for participating. Finally patients and relatives were asked whether they would participate again in similar circumstances.

Results: One third of the patients recalled having participated in a clinical trial. Thirteen per cent of the patients and $20 \%$ of the relatives felt that the information supplied had not been sufficient. Nine per cent of the patients and half the relatives had read the written information. None of the patients and one relative thought that participation had been obligatory. Twenty eight per cent of the patients and $94 \%$ of the relatives felt in retrospect that they had been capable of making an adequate decision. Virtually all patients and relatives would participate again in similar circumstances.

Conclusions: Many patients and their relatives have little recall of the informed consent procedure and the essentials of acute subarachnoid haemorrhage trials. However, most were satisfied with the overall procedure and would participate again.

A fundamental requirement for inclusion in a clinical trial is informed consent from patients or their representatives. Data on patients' perception of informed consent procedures are scarce, but the little information available shows that patients do not recall much of the trial they were involved in, even if they had ample time to consider their decision. $^{1-4}$

In patients randomised in the acute phase of aneurysmal subarachnoid haemorrhage, the ability to perceive details of a clinical trial may be impaired. Consequently, the likelihood that a patient with subarachnoid haemorrhage is in the end truly informed about a trial may be even smaller than in a patient who is not acutely ill and has ample time to make a decision. Having little recall about the trial is even more likely if the patient had a depressed level of consciousness at the time of randomisation, and informed consent is given by a representative instead.

We interviewed former participants of two randomised clinical trials on subarachnoid haemorrhage and their relatives about what trial information they could recall, how they had experienced the informed consent procedure, and whether they would take the same decision if asked again.

\section{METHODS}

\section{Patients}

We studied patients with subarachnoid haemorrhage admitted to the University Medical Centre Utrecht between November 1995 and November 1997, who had participated in either of two randomised clinical trials in that period. ${ }^{56}$ Both trials were double blind and placebo controlled and had been approved by the ethics committee of our hospital. Trial physicians who were not the attending physician sought informed consent within 96 hours after onset of the haemorrhage. The trial physicians and the setting of the informed consent procedure had been similar for both trials. If the patient had a normal level of consciousness, the presence of a relative was recommended but not mandatory. For patients who were not alert, informed consent was asked only from a relative. If a next of kin had participated in the informed consent procedure, this relative was also included in the study. We approached only patients who had regained an independent lifestyle after the haemorrhage.

The oral and written information given about the trial included an explanation about the disease; the name, effect, and side effects of the drug; the route of administration of the drugs; the placebo controlled and double blind design of the trial; the voluntary nature of participation; privacy regulation with regard to the case record forms; the duration of the trial; and the right to withdraw at any moment.

For the present study we first sent a letter to the patients and relatives. This letter explained that a follow up study would be performed. Patients who did not wish to be contacted could return a reply form. Two weeks after the letter was sent, we contacted the patients by telephone and asked if they agreed to participate; if so, an appointment for a home visit was made. The ethics committee of our hospital approved the study.

\section{Data collection}

All patients and relatives were interviewed at home by one of us (RS). Patients and relatives were interviewed together. The person who had originally given consent was asked to answer each question first.

The first question was whether the patient could recall having participated in a clinical trial. If not, the interviewer disclosed that the patient had indeed participated in such a trial, by referring to the encounter with a study physician shortly after admission to the hospital. Second, patients and relatives were asked to recount everything they could spontaneously recall about the trial. We recorded if the patient or 
Table 1 Results of the questionnaire used in the study

\begin{tabular}{|c|c|c|c|c|}
\hline & \multicolumn{2}{|c|}{ Patient consented } & \multicolumn{2}{|c|}{ Relative consented } \\
\hline & $\begin{array}{l}\text { Answer by } \\
\text { patient }(n=37)\end{array}$ & $\begin{array}{l}\text { Answer by } \\
\text { relative }(n=30)\end{array}$ & $\begin{array}{l}\text { Answer by } \\
\text { patient }(n=17)\end{array}$ & $\begin{array}{l}\text { Answer by } \\
\text { relative }(n=17)\end{array}$ \\
\hline \multicolumn{5}{|c|}{ Proportion of spontaneous recall of trial items* } \\
\hline Name of drug & $6(19)$ & $12(40)$ & $1(6)$ & $4(24)$ \\
\hline Effect of drug & $6(19)$ & $9(30)$ & $0(0)$ & $4(24)$ \\
\hline Placebo controlled design & $10(31)$ & $13(43)$ & $1(6)$ & $12(71)$ \\
\hline Double blind design & $4(13)$ & $6(20)$ & $0(0)$ & $7(41)$ \\
\hline Privacy & $0(0)$ & $0(0)$ & $0(0)$ & $0(0)$ \\
\hline Side effects & $0(0)$ & $0(0)$ & $0(0)$ & $0(0)$ \\
\hline Route of administration & $3(9)$ & $2(7)$ & $2(12)$ & $2(12)$ \\
\hline Voluntary participation & $2(6)$ & $3(10)$ & $0(0)$ & $3(18)$ \\
\hline Withdrawal possible & $0(0)$ & $0(0)$ & $0(0)$ & $0(0)$ \\
\hline Duration of trial & $1(3)$ & $0(0)$ & $0(0)$ & $0(0)$ \\
\hline \multicolumn{5}{|c|}{$\begin{array}{l}\text { Proportion of correct answer to questions on trial designt } \\
\text { Did you participate in a study? }\end{array}$} \\
\hline Yes & $14(38)$ & $24(80)$ & $4(24)$ & $12(70)$ \\
\hline No & $12(38)$ & $6(20)$ & $2(11)$ & $3(18)$ \\
\hline Don't know & $6(19)$ & $0(0)$ & $11(65)$ & $2(12)$ \\
\hline \multicolumn{5}{|l|}{ What was effect of the drug? } \\
\hline Correct & $6(19)$ & $14(47)$ & $0(0)$ & $6(35)$ \\
\hline Incorrect & $319)$ & $4(13)$ & $1(6)$ & $3(18)$ \\
\hline Don't know & $23(72)$ & $12(40)$ & $16(94)$ & $8(47)$ \\
\hline \multicolumn{5}{|c|}{ What proportion of participants was given in the study drug? } \\
\hline One half & $7(22)$ & 11 (37) & $1(6)$ & $7(41)$ \\
\hline Any other proportion & $1(3)$ & $3(10)$ & $2(12)$ & $2(12)$ \\
\hline Don't know & $24(75)$ & $16(53)$ & $14(82)$ & $8(47)$ \\
\hline \multicolumn{5}{|c|}{ Did you receive information about risks and benefits? } \\
\hline Yes & $8(25)$ & $19(64)$ & $0(0)$ & $12(70)$ \\
\hline No & $2(6)$ & $2(7)$ & $1(6)$ & $3(18)$ \\
\hline Don't know & $22(69)$ & $9(29)$ & $16(94)$ & $2(12)$ \\
\hline \multicolumn{5}{|c|}{ Who had access to the case record forms? } \\
\hline Correct & $4(13)$ & $9(30)$ & $1(6)$ & $2(12)$ \\
\hline Incorrect & $5(15)$ & $10(33)$ & $1(6)$ & $7(41)$ \\
\hline Don't know & $23(72)$ & $11(37)$ & $15(88)$ & 8147 \\
\hline \multicolumn{5}{|c|}{ What were possible side effects of the study drug? } \\
\hline Correct & $2(6)$ & $5(17)$ & $1(6)$ & $5(29)$ \\
\hline Incorrect & $2(6)$ & $4(13)$ & $0(0)$ & $3(18)$ \\
\hline Don't know & $28(88)$ & $21(70)$ & $16(94)$ & 9 (53) \\
\hline \multicolumn{5}{|l|}{ Was participation obligatory? } \\
\hline No & $19(59)$ & $23(77)$ & $0(0)$ & $16(94)$ \\
\hline Yes & $0(0)$ & $0(0)$ & $0(0)$ & $0(0)$ \\
\hline Don't know & $13(41)$ & $7(23)$ & $17(100)$ & $1(6)$ \\
\hline \multicolumn{5}{|c|}{ Was withdrawal after consent possible? } \\
\hline Yes & $8(25)$ & $15(50)$ & $1(6)$ & $6(35)$ \\
\hline \multirow{2}{*}{\multicolumn{5}{|c|}{ Don't know }} \\
\hline & & & & \\
\hline \multicolumn{5}{|c|}{ Answers to questions about opinions $\ddagger$} \\
\hline \multicolumn{5}{|c|}{ Was everything clear to you? } \\
\hline Yes & $8(25)$ & $20(65)$ & $1(6)$ & $11(65)$ \\
\hline No & $4(13)$ & $4(12)$ & $1(6)$ & $5(29)$ \\
\hline Don't know & $20(62)$ & $7(23)$ & $15(88)$ & $1(6)$ \\
\hline \multicolumn{5}{|c|}{ Was staff available to answer any questions? } \\
\hline Yes & $9(28)$ & $9(31)$ & $0(0)$ & $9(53)$ \\
\hline $\begin{array}{l}\text { No, no-one was available to } \\
\text { answer questions }\end{array}$ & $0(0)$ & $3(10)$ & $0(0)$ & $9(53)$ \\
\hline Don't know & $15(47$ & $6(21)$ & $16(94)$ & $0(0)$ \\
\hline Had no questions & $8(25)$ & $11(38)$ & $1(6)$ & 8 (47) \\
\hline In retrospect, had you wanted & re information? & & & \\
\hline & $4(13)$ & $6(20)$ & $0(0)$ & $3(18)$ \\
\hline No & $16(49)$ & $19(63)$ & $1(6)$ & $14(32)$ \\
\hline Don't know & $12(38)$ & $5(17)$ & $16(94)$ & $0(0)$ \\
\hline Did you receive written inform & & & & \\
\hline Yes & $3(9)$ & $13(43)$ & $0(0)$ & $9(53)$ \\
\hline No & $8(25)$ & $10(34)$ & $1(6)$ & $5(29)$ \\
\hline Don't know & $21(66)$ & $7(23)$ & $16(94)$ & $3(18)$ \\
\hline
\end{tabular}




\begin{tabular}{|c|c|c|c|c|}
\hline & \multicolumn{2}{|c|}{ Patient consented } & \multicolumn{2}{|c|}{ Relative consented } \\
\hline & $\begin{array}{l}\text { Answer by } \\
\text { patient }(n=37)\end{array}$ & $\begin{array}{l}\text { Answer by } \\
\text { relative }(n=30)\end{array}$ & $\begin{array}{l}\text { Answer by } \\
\text { patient }(n=17)\end{array}$ & $\begin{array}{l}\text { Answer by } \\
\text { relative }(n=17)\end{array}$ \\
\hline \multicolumn{5}{|c|}{$\begin{array}{l}\text { Did you read the written } \\
\text { information? }\end{array}$} \\
\hline Yes & 3 (9) & $13(43)$ & $0(0)$ & $8(47)$ \\
\hline No $\quad$ & $0(0)$ & $0(0)$ & $0(0)$ & $1(6)$ \\
\hline Don't know & $21(66)$ & 8 (27) & $16(94)$ & $3(18)$ \\
\hline \multicolumn{5}{|c|}{$\begin{array}{l}\text { Did you feel participation was } \\
\text { voluntary? }\end{array}$} \\
\hline Yes & $16(50)$ & $23(77)$ & \# & $15(88)$ \\
\hline No & $0(0)$ & $0(0)$ & \# & $1(6)$ \\
\hline Don't know & $16(50)$ & $7(23)$ & \# & $1(6)$ \\
\hline \multicolumn{5}{|c|}{ Were you capable of deciding about participation? } \\
\hline Yes & $9(28)$ & $23(78)$ & \# & $16(94)$ \\
\hline No & 7 (22) & $3(9)$ & \# & $1(6)$ \\
\hline Don't know & $16(50)$ & $4(13)$ & $\#$ & $0(0)$ \\
\hline \multicolumn{5}{|c|}{ Do you think the informed consent procedure should be changed? } \\
\hline Yes & $3(9)$ & $12(41)$ & $0(0)$ & $4(24)$ \\
\hline No & 7 (22) & $14(45)$ & $0(0)$ & $12(70)$ \\
\hline Don't know & $22(69)$ & $4(14)$ & $17(100)$ & $1(60)$ \\
\hline \multicolumn{5}{|c|}{ Would you participate again? } \\
\hline Yes & $31(97)$ & 28193 & $16(94)$ & $16(94)$ \\
\hline No & $1(3)$ & $2(7)$ & $1(6)$ & $1(6)$ \\
\hline Don't know & $0(0)$ & $0(0)$ & $0(0)$ & $0(0)$ \\
\hline \multicolumn{5}{|c|}{ How readable was the written information? } \\
\hline Easy to read & $29(91)$ & $28(94)$ & $16(93)$ & $17(100)$ \\
\hline Hard to read & $2(6)$ & $1(3)$ & $0(0)$ & $0(0)$ \\
\hline Neutral & $1(3)$ & $1(3)$ & $1(7)$ & $0(0)$ \\
\hline \multicolumn{5}{|c|}{$\begin{array}{l}\text { How do you assess participation } \\
\text { in retrospect? }\end{array}$} \\
\hline Positive & $25(78)$ & $24(80)$ & $17(100)$ & $14(82)$ \\
\hline Negative & $0(0)$ & $1(3)$ & $0(0)$ & $0(0)$ \\
\hline Neutral & 7 (22) & 5 (17) & $0(0)$ & $3(18)$ \\
\hline \multicolumn{5}{|c|}{$\begin{array}{l}\text { Values are } \mathrm{n}(\%) \text { of patients or relatives who recalled the item spontaneously and correctly. } \\
\text { *The numbers are patients or relatives who recall the item spontaneously and correctly; percentages are } \\
\text { given in parentheses. } \\
\text { \# Does not apply because relative consented. } \\
\text { tThe numbers are patients or relatives who recalled the item, items are abbreviated versions of the original in } \\
\text { Dutch. } \\
\text { tThe numbers are patients or relatives who mentioned the item, percentages are given in parentheses. Items } \\
\text { are abbreviated versions of the original questions in Dutch. }\end{array}$} \\
\hline
\end{tabular}

relative mentioned any of 10 items listed in the upper part of table 1. Third, by means of a standardised questionnaire, we asked questions on trial design, appreciation of the study, and on the reasons for participation in the trial.Finally the interviewer once more provided all original oral and written information on the trial and subsequently asked the patients and relatives whether they would participate again, under similar circumstances.

\section{Data analyses}

We categorised the answers according to whether the patient or a relative had given consent, and listed answers of patients and relatives separately.

\section{RESULTS}

\section{Patients and relatives}

Fifty seven patients fulfilled the inclusion criteria. Seven patients declined to participate, and one could not be traced. We thus included 49 patients; for 47 of these we were able to interview the relative as well. Seven of the 47 relatives had not been involved in the initial informed consent procedure; in retrospect three of these would have liked to have been involved. The median time between the disease episode and the time of the interview was 20 months (range 7 to 31 months). Informed consent had been given in 32 instances by the patient and in 17 by a relative.

\section{Spontaneous recall}

One third of the patients recalled spontaneously having participated in a trial. The name of the drug and the placebo controlled design were the items most often spontaneously recalled. No patient or relative spontaneously mentioned the possibility of withdrawal or the privacy regulations.

\section{Answers to structured questions}

Many patients recalled details of the study only after the interviewer had disclosed that the patient had indeed participated in a clinical trial. Patients who consented themselves gave more correct answers on the trial design questions than patients whose relative had given consent.

\section{Knowledge of trial design}

Relatives more often answered questions on trial design correctly than patients, not only when the relative had given consent, but also when the patient had done so. Four patients and six relatives felt that information had not been sufficient. Nine per cent of the patients and half the relatives had read the written information. One relative but none of the patients had felt that participation was obligatory. 


\section{Assessment of participation}

Twenty eight per cent of the patients and $94 \%$ of the relatives felt they had been capable of making an adequate decision during the informed consent procedure. None of the patients and only one relative had negative feelings about participation in the clinical trial. All 17 patients who had been incapable of making a decision were satisfied that a relative had given consent.

\section{Reasons for participation}

"To help medical science" was mentioned most often by patients ( 10 times, or $50 \%$ ) and relatives (16 times, or $36 \%$ ). Seven patients (35\%) and 12 relatives (27\%) spontaneously mentioned personal benefit from the trial as a reason to participate.

\section{Appreciation of the informed consent procedure}

Six of the 32 patients (19\%) who had given consent themselves could remember the informed consent procedure; none of these patients had negative feelings towards the procedure. Four relatives (17\%) could not remember the procedure. Eleven of the relatives (65\%) who gave consent assessed the informed consent procedure as positive, four as neutral $(23 \%)$, and two as negative (12\%). Under similar circumstances $97 \%$ of patients and relatives would participate again.

\section{DISCUSSION}

We found that many patients and relatives have incomplete recall of the essentials of the trial and the treatment used. Nevertheless, most were satisfied with the amount of information they had received at the time of giving consent and would participate again in similar circumstances.

Several factors may explain the poor recall of the study details. Even in secondary prevention trials where patients have ample time to consider participation, recall of study details is often poor. ${ }^{1-4}$ Being admitted with an acute life threatening disease may further decrease the ability to understand or retain information. Another explanation is that transient amnesia can occur even in alert patients with subarachnoid haemorrhage; this is related to enlargement of the temporal horns.

Most patients would participate again, even though some were dissatisfied with the information given. Some characteristics of the study may have influenced the large proportion of patients who would participate again. Patients and their relatives knew that the interviewer was connected with the hospital, which may have led them to give socially desirable answers. A related source of bias is that patients were loyal towards their relatives, where the relatives had given consent. Also, we interviewed only patients who were independent after the episode of subarachnoid haemorrhage (and their relatives). Patients with a good outcome are likely to have a positive appreciation of life and consequently see participation in the trial in a positive light. Because satisfaction with participation in a trial is mostly based on patients' previous expectations and general attitudes towards medical care and research and not on improvement in health, ${ }^{8}$ we do not think these factors influenced our results markedly. Another limitation of our study is that we excluded patients and relatives who had declined to participate in either of the clinical trials. This may also have increased the reporting of positive feelings about the trial and the informed consent procedure. The two year interval between the haemorrhage and the time of the interview may have contributed to the poor recall of the details of the trial, but at that stage clinical recovery is more complete than after only a few months. ${ }^{9}$

The apparent lack of knowledge does not necessarily mean that patients should be informed more extensively in the acute phase. Apart from the right to be informed, patients and relatives must also have the right to disregard information in periods of fear and anxiety. This is supported by the infrequent use of the written information. At later stages information should be available for patients, if they wish. Patients should know whom to contact and how, in case questions arise later.

\section{ACKNOWLEDGEMENTS}

This study was in part supported by an established clinical investigator grant from the Netherlands Heart Foundation to GJER (grant D98.014).

\section{Authors' affiliations}

R Schats, E H Brilstra, G J E Rinkel, A Algra, J van Gijn, Department

of Neurology University Medical Centre Utrecht, Utrecht, Netherlands

Competing interests: none declared

Correspondence to: Professor Gabriel J E Rinkel, Department of Neurology, University Medical Centre Utrecht, PO Box 85500, 3500 GA Utrecht, Netherlands; g.j.e.rinkel@neuro.azu.nl

Received 11 October 2002

In revised form 21 February 2003

Accepted 25 February 2003

\section{REFERENCES}

1 Oddens BJ, Algra A, van Gijn J. How much information is retained by participants in clinical trials? Ned Tijdschr Geneeskd 1992;136:22726.

2 Oddens BJ, Algra A, van Giin J. Informing patients about clinical trials. Clin Invest 1993;71:572-3.

3 Hekkenberg RJ, Irish JC, Rotstein LE, et al. Informed consent in head and neck surgery: how much do patients actually remember? J Otolaryngol 1997:26:155-9.

4 Lashley M, Talley W, Lands LC, et al. Informed proxy consent: communication between pediatric surgeons and surrogates about surgery. Pediatrics 2000;105:591-7.

5 Hop JW, Rinkel GJE, Algra A, et al. Randomised pilot trial of postoperative aspirin in subarachnoid hemorrhage. Neurology 2000;54:872-8

6 Roos Y, STAR Study Group. Antifibrinolytic treatment in subarachnoid hemorrhage. A randomised placebo-controlled trial. Neurology 2000;54:77-82.

7 Hop JW, Brilstra EH, Rinkel GJE. Transient amnesia after perimesencephalic haemorrhage: the role of enlarged temporal horns. J Neurol Neurosurg Psychiatry 1998;65:590-3.

8 Verheggen FW, Nieman FH, Reerink E, et al. Patient satisfaction with clinical trial participation. Int J Qual Health Care 1998;10:319-30.

9 Hop JW, Rinkel GJE, Algra A, et al. Changes in functional outcome and quality of life in patients and caregivers after aneurysmal subarachnoid hemorrhage. J Neurosurg 2001;95:957-63. 